\title{
Are educational or quality improvement interventions delivered at the induction or orientation of junior doctors effective?
}

\author{
Luke McMenamin $^{1}$, Natalie Blencowe ${ }^{2}$, Damian Roland ${ }^{3}$ \\ 1. Leeds Institute of Medical Education, University of Leeds, Leeds, UK. 2. Centre for Surgical Research, School of Social \\ and Community Medicine, University of Bristol, UK. 3. Paediatric Emergency Medicine Leicester Academic (PEMLA) Group, \\ EMAG, Cardiovascular Sciences, Leicester University, UK.
}

Correspondence: Damian Roland. Address: Paediatric Emergency Medicine Leicester Academic (PEMLA) Group, EMAG, Cardiovascular Sciences, Leicester University, UK LE1 5WW. E-mail: dr98@leicester.ac.uk

Received: January 30, 2014

DOI : $10.5430 /$ jha.v3n5p14
Accepted: March 11, 2014

URL: http://dx.doi.org/10.5430/jha.v3n5p14

\section{Abstract}

There has been significant media scrutiny in the UK of the period when doctors change over into new jobs, with a number of reports highlighting increased mortality. Starting work in a new hospital confers a potential patient safety risk and induction programmes are therefore designed to familiarise doctors with local policies. Little is known about using this time as an opportunity to improve patient outcomes or change practice. The aim was to review interventions which may aid hospital trusts during induction and a strategy to direct future educational and implementation research. A review of Medline, Embase, Cochrane, Scopus and ERIC databases with key terms (induction or orientation, junior doctor or intern, intervention or education or implementation, quality improvement or patient safety or outcome) extracted relevant abstracts. Articles of relevance were analysed and coded as to the type of patient or doctor group, intervention and outcome. Only seven studies were found which generally reported perceived benefits rather than objective outcomes. A significant opportunity to improve evidence based practice and patient safety is being missed by not thoroughly evaluating the impact of induction and orientation of health care professionals.

\section{Key words}

Medical education, Doctors, Induction, Orientation, Quality improvement

\section{Introduction}

During the month of August the media ${ }^{[1]}$ and other organisations closely scrutinise the performance of the National Health Service (NHS), as during this period new medical graduates enter the foundation programme and doctors' changeover occurs. Some describe it as the "August killing season" ${ }^{[2]}$ or "Black Wednesday" (referring to the first Wednesday that they start work) and in the US it is known as the "July effect" or "July phenomenon". There is evidence to suggest that hospital mortality rates increase during this timeframe, and efficiency decreases ${ }^{[3,4]}$. Unnecessary deaths occurring in hospitals at this time of year has recently lead to a Coroner's Court questioning the training new doctors receive during their first few weeks of work ${ }^{[5]}$. As well as the potential risk to patient safety, commencing in a new hospital can be a stressful time for the doctors ${ }^{[6]}$, who feel overwhelmed and underprepared which potentially affect their quality of life ${ }^{[7]}$. 
Induction programmes, designed to deliver a large quantity of information in a short period of time, have been mandatory for all new doctors since $1997^{[8]}$. More recently, the General Medical Council (GMC) recommended a period of shadowing before graduation, to familiarise the student doctor with the ward environment and, ideally, the job that they will later undertake ${ }^{[9]}$. Little is known, however, about whether periods of induction or shadowing improve patient outcomes or change practice ${ }^{[10]}$.

\section{Aim}

This review aimed to summarise published literature on induction programmes for doctors and asks the question, "are the interventions delivered effective?”

\section{Methods}

\subsection{Search strategy}

The Ovid version of MEDLINE (1950 to present), the Cochrane Central Register of Controlled Trials (Issue 12, 2011), Embase, Scopus and ERIC databases were searched using key words and Mesh terms for induction, training and orientation which were combined using the "OR" operator. These were all combined with search terms for "doctor" using the "AND” operator. Search filters for randomised trials (RCTs), prospective studies and quality improvement were also applied to ensure that all study designs were identified. Searches were limited to human studies published in English, although the date was not restricted. The search strategy is shown in Figure 1. Duplicate records were removed and the titles and abstracts of citations screened for eligibility by one researcher, using pre-determined selection criteria. Because this is an uncommon topic area and well-defined search strategies do not exist, hand searching of reference lists of included studies was also performed.

Figure 1. Search strategy (Medline Version)

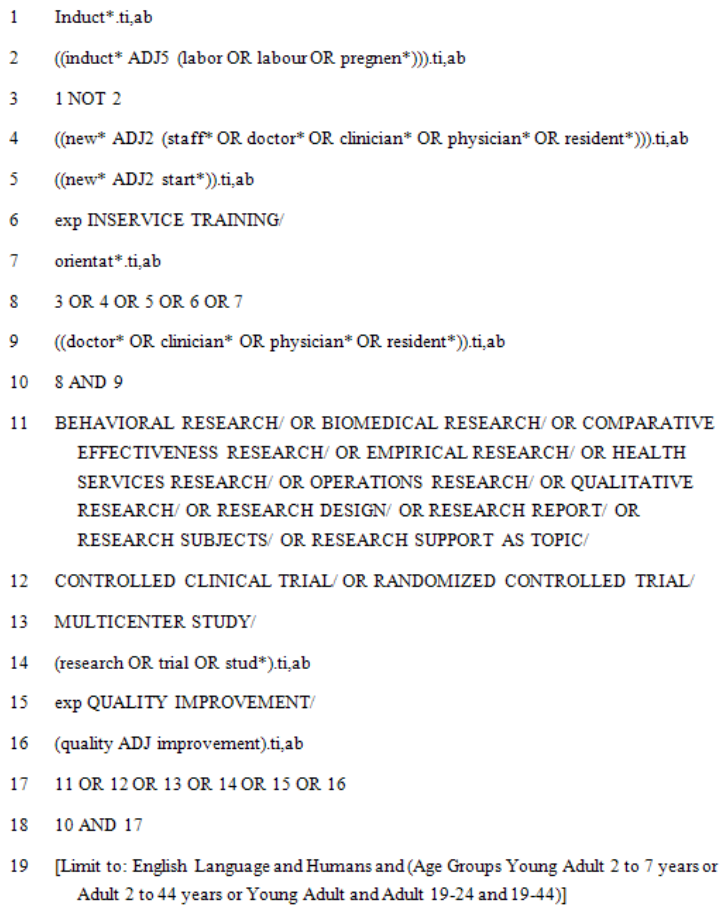

\subsection{Inclusion of papers}

Included were studies either describing or reporting outcomes of induction programmes for doctors. Studies providing information about induction programmes for other healthcare professionals were excluded. Papers including induction 
programmes involving a range of healthcare professionals were excluded unless the description or outcomes pertaining to doctors were reported separately. Each abstract was independently read by at least one author and full text articles meeting the inclusion criteria analysed by two authors.

\subsection{Data extraction}

The intervention and numbers of doctors were recorded for each study. Precise details about the nature of the intervention were extracted, including its time scale, location and format. Information relating to evaluation of the intervention was also documented and, where applicable, results were recorded. Differences between reviewers were resolved by consensus.

\section{Results}

Titles and abstracts of 90 papers were identified, 15 full papers obtained and six articles included. One additional article was identified from hand searching reference lists of included articles (see Figure 2).

Figure 2. Flow Diagram of papers throughout the review, according to the PRISMA criteria ${ }^{[11]}$

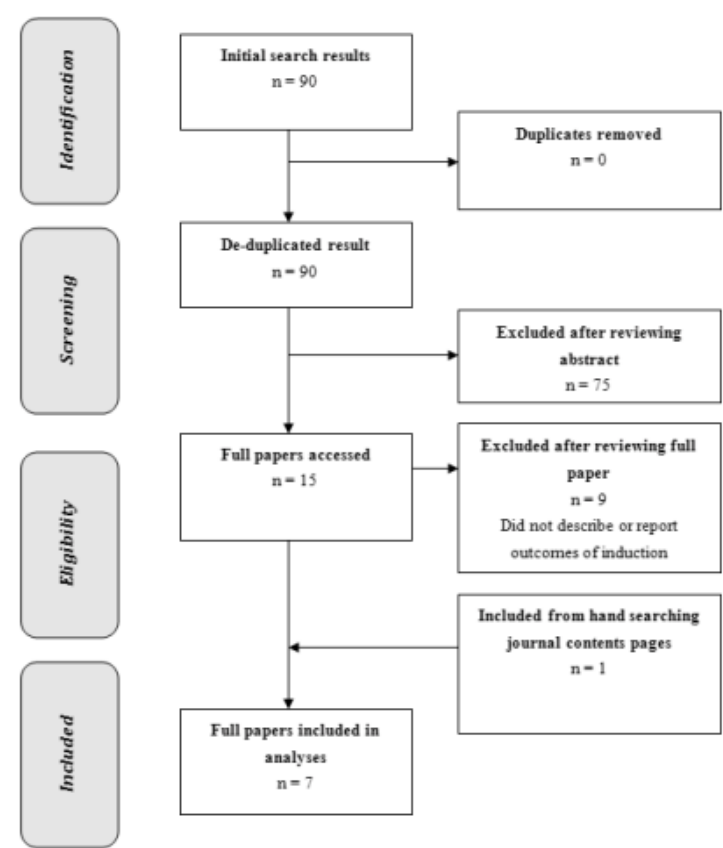

Table 1. General study details

\begin{tabular}{|c|c|c|c|c|}
\hline First Author & Year of publication & Number of Participants & Country & Stage of training \\
\hline Madhok et al. & 1993 & 131 & UK & Foundation Year Doctors \\
\hline Berridge et al. & 2007 & 50 & UK & New Doctors \\
\hline Day et al. & 2010 & 12 & UK & Speciality Trainee Doctors \\
\hline Abu-Habsa et al. & 2010 & 60 & UK & Acute Care Common Stem Trainees \\
\hline Magill et al. & 2012 & N/A & UK & Foundation Year Doctors \\
\hline Byrne et al. & 2012 & 100 & Ireland & New Doctors \\
\hline Weaver et al. & 2012 & N/A & USA & New Doctors \\
\hline
\end{tabular}

Note. UK = United Kingdom, USA = United States of America, N/A = Not reported

The seven included articles reported data from a total of 353 healthcare professionals (see Table 1). All studies described an educational intervention for trainee doctors. Of these, three were designed for new doctors, and four provided training in preparation for subspecialty jobs (see Table 1). Five involved face-to-face teaching, one was a computerbased e-learning module ${ }^{[12]}$, and one was distribution of guidelines ${ }^{[13]}$. All of the interventions took place within the clinical setting, prior to the doctors either beginning work for the first time ${ }^{[13-17]}$ or just before they began work in a 
new speciality ${ }^{[12,18]}$. The face-to-face teaching interventions varied in length from one day to two weeks. None of the interventions involved formal assessment of the trainees’ knowledge after completion.

\subsection{Range of evaluation processes used in the studies}

One of the articles did not include details relating to evaluation of the education intervention it described ${ }^{[18]}$. The authors stated that "...candidates demonstrated greater confidence" but this was interpreted as an ad-hoc comment rather than formal evaluation, as no other information was provided. Of the six studies providing this information, all used non-randomised designs. Four administered questionnaires to the doctors attending the training ${ }^{[12,13,15,17]}$. However, none of these were validated and only one was conducted both before and after the intervention ${ }^{[15]}$. Another study used service evaluation research to assess if the induction orientation had a direct impact on patient care ${ }^{[16]}$. The last study used a mixed method design comprising focus groups and questionnaires with the aim of capturing a deeper understanding the impact of the intervention had on the participants ${ }^{[14]}$.

\subsection{Outcomes of the interventions}

Results of the interventions are described in Table 2. Only one study assessed the influence of the intervention on patient care. Two described that the interventions were deemed to be "acceptable" and a "positive experience". The intervention in which doctors were trained to use guidelines provided compliance rates to their use. Self-reported confidence of doctors was reported to increase following the intervention in two studies, with another stating that "preparedness" improved.

Table 2. Details of how the authors evaluated their interventions

\begin{tabular}{|c|c|c|c|c|c|}
\hline $\begin{array}{l}\text { First } \\
\text { Author }\end{array}$ & $\begin{array}{l}\text { Evaluation } \\
\text { Method }\end{array}$ & $\begin{array}{l}\text { Response } \\
\text { Rate (\%) }\end{array}$ & $\begin{array}{l}\text { Evaluation time } \\
\text { point(s) }\end{array}$ & What outcome was evaluated? & Results \\
\hline Madhok & Questionnaire & 80 & $\begin{array}{l}\text { Two months after the } \\
\text { distribution of the } \\
\text { guidelines }\end{array}$ & $\begin{array}{l}\text { Number of doctors who used the } \\
\text { guidelines in the clinical environment }\end{array}$ & $63 \%$ used the guidelines \\
\hline Berridge & Questionnaire & 94 & $\begin{array}{l}\text { The beginning and at the } \\
\text { end of the two week } \\
\text { programme. Further } \\
\text { evaluation occurred one } \\
\text { month after the } \\
\text { programmes } \\
\text { completion. }\end{array}$ & $\begin{array}{l}\text { The questionnaire evaluated the } \\
\text { impact of the course had on their self } \\
\text { perceived preparedness. The focus } \\
\text { group explored a deeper understanding } \\
\text { of the participants' fears and how the } \\
\text { programme attempted to help them } \\
\text { overcome them. }\end{array}$ & $\begin{array}{l}\text { The new doctors' perceived } \\
\text { preparedness and confidence } \\
\text { increased after the two week } \\
\text { programme in both the } \\
\text { questionnaire responses and } \\
\text { the focus groups discussions }\end{array}$ \\
\hline Day & Questionnaire & 100 & After the intervention & $\begin{array}{l}\text { Could the e-learning tool be an } \\
\text { acceptable alternative to a lecture } \\
\text { programme? }\end{array}$ & $\begin{array}{l}\text { The speciality trainees } \\
\text { perceived that the intervention } \\
\text { was acceptable }\end{array}$ \\
\hline $\begin{array}{l}\text { Abu- } \\
\text { Habsa }\end{array}$ & N/A & N/A & $\begin{array}{l}\text { On the day of the course, } \\
\text { first day of the job, end } \\
\text { of week } 1 \text {, week } 6 \text { and } 4 \\
\text { months into the new } \\
\text { acute care training post. }\end{array}$ & $\begin{array}{l}\text { Self perceived preparedness for } \\
\text { providing acute care }\end{array}$ & $\begin{array}{l}\text { Candidates reported greater } \\
\text { self confidence in performing } \\
\text { practical critical care skills }\end{array}$ \\
\hline Magill & $\begin{array}{l}\text { Service } \\
\text { evaluation }\end{array}$ & N/A & $\begin{array}{l}\text { Audited the } \\
\text { management of patients } \\
\text { for two months before } \\
\text { and two months after the } \\
\text { mandatory teaching. }\end{array}$ & $\begin{array}{l}\text { Comparing the management of ENT } \\
\text { patients before and after the mandatory } \\
\text { teaching }\end{array}$ & $\begin{array}{l}38 \% \text { of patients were } \\
\text { mismanaged before and 19\% } \\
\text { of patients were mismanaged } \\
\text { after the intervention. }\end{array}$ \\
\hline Byrne & Questionnaire & 94 & $\begin{array}{l}\text { Before and after the four } \\
\text { week mandatory } \\
\text { teaching and shadowing }\end{array}$ & $\begin{array}{l}\text { Self perceived preparedness for the } \\
\text { role of a junior doctor }\end{array}$ & $\begin{array}{l}52.5 \% \text { perceived themselves } \\
\text { to be prepared prior to the } \\
\text { intervention whereas } 79.7 \% \\
\text { perceived themselves to be } \\
\text { prepared after the mandatory } \\
\text { teaching and shadowing }\end{array}$ \\
\hline Weaver & Questionnaire & $\mathrm{N} / \mathrm{A}$ & $\begin{array}{l}\text { After the coaching } \\
\text { programme }\end{array}$ & $\begin{array}{l}\text { Did the new hospital doctors find the } \\
\text { coaching system an enjoyable } \\
\text { experience? }\end{array}$ & $\begin{array}{l}83 \% \text { felt the intervention was } \\
\text { a positive experience }\end{array}$ \\
\hline
\end{tabular}




\section{Discussion}

There was little research on the effectiveness of induction or orientation programmes, especially in respect of well conducted controlled studies. Studies that had been performed looked at participant perception rather than patient benefit. This finding is not completely unexpected as induction is often a mandatory undertaking performed at the request of regulatory bodies rather than a process of delivered learning. The complexity of delivering training to a large number of doctors simultaneously makes the pedagogical approach didactic and perhaps not of interest to educators or those interested in quality improvement.

The lack of outcome focused research is in keeping with many reviews of educational interventions ${ }^{[19-21]}$. However, the difficulty in undertaking this research should not prevent it from happening.

\section{Conclusion}

Given the resources (both financial and time) expended on the national induction programme which are at the tax payers' expense, it is important to know that beneficial results are achieved. Alternatively, it could be argued that direct patient benefit should not be the overall aim ${ }^{[22]}$ and it is the delivery of effective education that is the critical objective of the induction programme. Regardless the lack of the research in this area is surprising. We recommend that all UK healthcare institutions should evaluate their induction programmes, in particular respect of patient safety and participant behaviour. Well constructed educational and improvement methodologies should be employed utilising the large numbers of participants on these programmes. Moreover, examples of successful orientation or induction interventions should be reported and rewarded so that other institutions can emulate good practice.

The ambition for all healthcare institutions should be to improve the transition of doctors, and all health care professionals, between different stages of training, clinical placements and hospitals in order to improve the quality and safety of care delivered to the patients.

\section{Conflict of interests}

The authors declare that they have no conflict of interests.

\section{References}

[1] Hough A. New junior doctor rules 'will stop NHS killing season'. 2012; Available from: http://www.telegraph.co.uk/health/healthnews/9350659/New-junior-doctor-rules-will-stop-NHS-killing-season.html. 31 July 2013.

[2] Aylin P., Majeed F.A. The killing season--fact or fiction? BMJ. 1994; 309(6970): 1690. http://dx.doi.org/10.1136/bmj.309.6970.1690

[3] Jen M.H., Bottle A., Majeed A., et al. Early in-hospital mortality following trainee doctors' first day at work. PLoS One. 2009; 4(9): e7103. PMid: 19774078. http://dx.doi.org/10.1371/journal.pone.0007103

[4] Young J.Q., Ranji S.R., Watcher R.M., et al. "July Effect”: Impact of the Academic Year-End Changeover on Patient OutcomesA Systematic Review. Ann Intern Med. 2011; 155(5): 309-315. PMid: 21747093.

http://dx.doi.org/10.7326/0003-4819-155-5-201109060-00354

[5] DHSSPS. Report On Induction Processes For Medical Staff In The HPSS 2006. 5 January 2014; Available from: http://www.gmc-uk.org/DV011_Enclosure_2__Induction_report_final.pdf_30940297.pdf.

[6] Houston D.M., Allt S.K. Psychological distress and error making among junior house officers. Br J Health Psychol. 1997; 2(2): 141-151. http://dx.doi.org/10.1111/j.2044-8287.1997.tb00530.x

[7] Paice E., Rutter H., Wetherell M., et al. Stressful incidents, stress and coping strategies in the pre - registration house officer year. Med Educ. 2002; 36(1): 56-65. PMid: 11849525. http://dx.doi.org/10.1046/j.1365-2923.2002.01101.x

[8] GMC. The New Doctor. London: GeneralMedical Council. 1997. 
[9] GMC. Tomorrow's doctors. London: GeneralMedical Council. 2009.

[10] Ward S.J., Stanley P. Induction for senior house officers. Part I: The hospital programme. Postgrad Med J. 1999; 75(884): 346-350. PMid: 10435169.

[11] Moher D., Liberati A., Tetzlaff J., et al. Preferred reporting items for systematic reviews and meta-analyses: the PRISMA statement. Ann Intern Med. 2009; 151(4): 264-269. PMid: 19622511. http://dx.doi.org/10.7326/0003-4819-151-4-200908180-00135

[12] Day S., Rayment M., Mohabeer M., et al. Specialty induction for junior doctors in GUM/HIV medicine using an e-learning tool. J HIV Med. 2010; 11: 102-103.

[13] Madhok R., Thomson R., Mordue A., et al. An audit of distribution and use of guidelines for management of head injury. Qual Health Care. 1993; 2(1): 27-30. PMid: 10132074. http://dx.doi.org/10.1136/qshc.2.1.27

[14] Berridge E-J., Freeth D., Sharpe J, et al. Bridging the gap: supporting the transition from medical student to practising doctor-a two-week preparation programme after graduation. Med Teach, 2007; 29(2-3): 119-127. PMid: 17701621. http://dx.doi.org/10.1080/01421590701310897

[15] Byrne D., O'Connor P., Lydon s., et al. Preparing new doctors for clinical practice: an evaluation of pre-internship training. Ir Med J. 2012; 105(10): 328-30. PMid: 23495542.

[16] Magill J., Slovick A., Daly N. ENT out of hours cross-cover by non-ENT junior doctors at a District General Hospital (DGH): before and after a compulsory induction in ENT emergency management with local guideline production. Clin Otolaryngol. 2012; 37: 55-56.

[17] Weaver C., Cyrus R., Kier S., et al. A hospitalist clinical coach program for new faculty. J Hosp Med. 2012; 7: S138-S139.

[18] Abu-Habsa M., Harrison E. A single-day course designed with a modified delphi method preceding a critical care post improves novice trainees' performance and confidence. Intensive Care Med. 2010; 36.

[19] Gillan C., Lovrics E., Halpern E., et al. The evaluation of learner outcomes in interprofessional continuing education: A literature review and an analysis of survey instruments. Med Teach. 2011; 33(9): e461-e470. PMid: 21854139. http://dx.doi.org/10.3109/0142159X.2011.587915

[20] Mansouri M., Lockyer J. A meta - analysis of continuing medical education effectiveness. J Contin Educ Health Prof. 2007; 27(1): 6-15. PMid: 17385735. http://dx.doi.org/10.1002/chp.88

[21] Reed D., Price E.G., Windish D.M., et al. Challenges in systematic reviews of educational intervention studies. Ann Intern Med. 2005; 142(12_Part_2): 1080-1089.

[22] Cook D.A., West C.P. Perspective: Reconsidering the Focus on “Outcomes Research” in Medical Education: A Cautionary Note. Acad Med. 2013; 88(2): 162-167. PMid: 23269304. http://dx.doi.org/10.1097/ACM.0b013e31827c3d78 